\title{
IDENTIFIKASI POTENSI WISATA DESA TANGKUP KARANGASEM MENUJU DESA WISATA RINTISAN
}

\author{
Ni Wayan Mekarini ${ }^{\left.1^{*}\right)}$, Putu Agus Prayogi ${ }^{2}$, I Ketut Sutapa ${ }^{3}$ \\ (Fakultas Pariwisata Universitas Triatma Mulya ${ }^{\mathbf{1 , 2 , 3}}$ ) \\ wayan.mekarini@triatmamulya.ac.id ${ }^{*}$
}

\begin{abstract}
Tangkup Village has an area of 2,667 Km2, most of which is in the form of rice fields. The natural tourism potential of Tangkup Village is a rice field area located in Tangkup Anyar, a watershed located in Tangkup Desa area, and green hills that surround the village. Cultural potential in the form of cagcag woven cloth which is a typical product of Tangkup, traditional snacks called jaje tulud, tipat pesor and sangait. In other places, sangait is made from sweet potatoes, Sangait in Tangkup village is made from cassava which is widely grown by local people. However, in the process of developing this snack product, it encountered obstacles related to the dough that did not support the process of design tulud cakes with coconut shells. Even though the community wants to develop jaja tulud, the tools used should not be replaced. Because of these difficulties, not many residents survive to make jaja tulud which is usually used for ceremonial needs. Regarding its function as a typical snack, students want to develop this snack so that it can be of economic value and accepted by tourists through a more elegant presentation. Students are actively involved in the preparation for the formation of Pokdarwis so that the direction of village development is towards a managed and directed tourism village. So far, the potential management of Tangkup Village is still being handled independently by utilizing the land owned, especially those located near watersheds, in the form of cafes, rafting, Asta Gangga Park attractions and bamboo houses that are being built as tourist facilities on the hill. The village hopes that students will help generate the tourism potential of Tangkup Village, so that it is widely known and visitors enjoy the beauty of this beautiful fertile village through the preparation of local human resources to welcome Tangkup village which will soon become a tourist village.
\end{abstract}

Keywords: Tangkup village, natural potential, cultural potential, tourism village.

\section{PENDAHULUAN}

Salah satu daerah yang sedang melakukan proses pengembangan desa menjadi desa wisata adalah Desa Tangkup. Desa Tangkup memilki sumber daya alam yang sangat potensial untuk dikembangkan dan dijadikan sumber pendapatan desa. Sumber alam tersebut apabila tidak dikelola dengan baik dan tanpa sentuhan konsepsi pembangunan yang berwawasan lingkungan maka akan memberikan dampak yang merugikan bagi lingkungaa hidup sekitar. Desa Tangkup tergolong subur karena dialiri oleh air yang bersumber dari tukad Telaga Waja dan tukad Unda serta terdapat sembilan sumber mata air yang debitnya cukup besar di sekitar desa menjadikan persediaan air melimpah sepanjang tahun. Karena kesuburannya dahulu Desa Tangkup diperebutkan oleh Kerajaan 


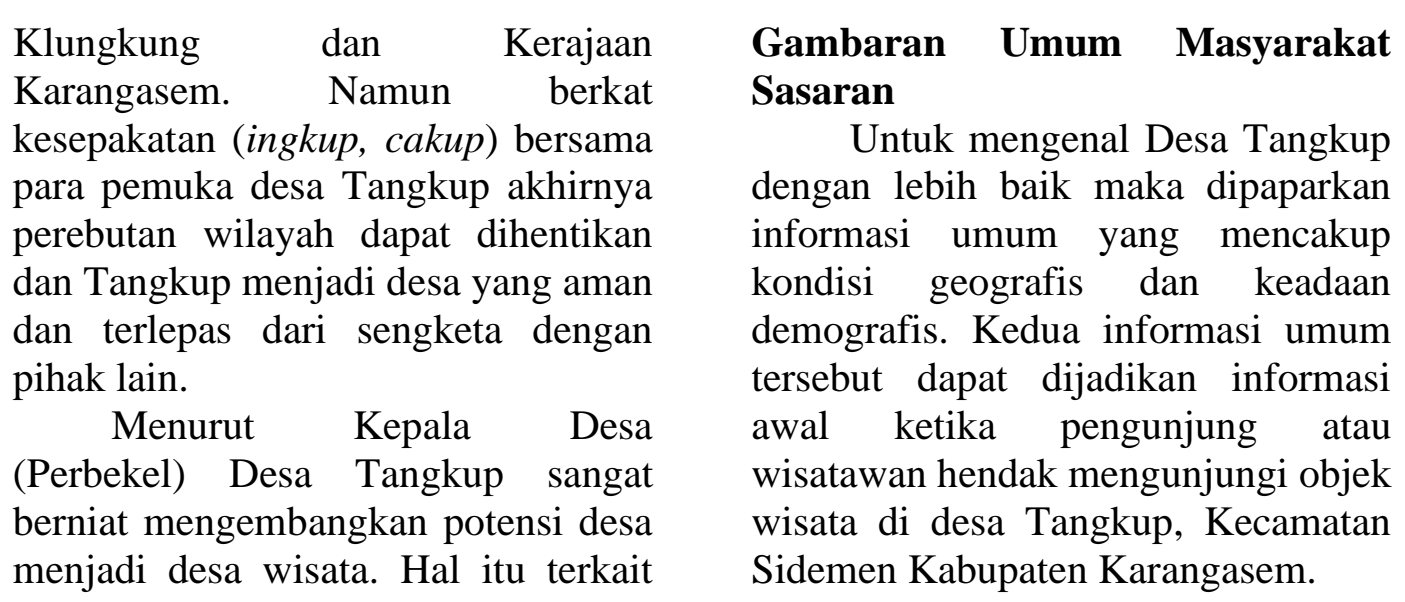
dengan dorongan pemerintah mengembangkan program Desa Wisata berbasis masyarakat lokal sehingga SDM lokal bergerak maju sebagai pengelola. Desa wisata merupakan suatu bentuk integrasi antara atraksi, akomodasi dan fasilitas pendukung yang disajikan dalam suatu struktur kehidupan masyarakat yang menyatu dengan tata cara dan tradisi yang berlaku. Kehadiran mahasiswa yang melaksanakan Program Kuliah Kerja Nyata (KKN) sebagai pengabdian kepada masyarakat dipandang dapat membantu mewujudkan harapan menjadi desa wisata. Langkah awal yang diambil mahasiswa bersepakat dengan pihak kepala desa adalah dengan mengidentifikasi potensi alam dan budaya yang kemudian diteruskan dengan program-program lain yang beorientasi pada tujuan mengantarkan desa Tangkup menjadi desa wisata.

\section{a. Kondisi Geografis}

Bila dilihat dari segi geografisnya, Desa Tangkup berada pada ketinggian kurang lebih 500700 meter dari permukaan laut, Topografi Desa Tangkup secara keseluruhan wilayah merupakan dataran rendah dengan kemiringan $0,5 \%$, dengan curah hujan rata-rata 2000-3000 $\mathrm{mm}$ per tahun, dan keadaan suhu rata - rata $36^{\circ} \mathrm{C}$. Desa Tangkup memiliki batas - batas wilayah di bagian utara yaitu Desa Sangkan Gunung, bagian timur yaitu Desa Wisma Kerta, bagian selatan yaitu Sungai Unda, dan pada sebelah barat terdapat Sungai Telaga Waja. Desa Tangkup adalah salah satu Desa di kecamatan Sidemen yang memiliki luas wilayah 2,667 Ha yang terbagi atas 4 Banjar Dinas yakni Banjar Sangkungan, Banjar Dinas Tabu, Banjar Dinas Tangkup Anyar dan Banjar Dinas Tangkup Desa. Luas wilayah desa Tangkup disajikan dalam tabel berikut. 


\section{Tabel 1}

Luas Wilayah Desa Tangkup

\begin{tabular}{rll}
\hline \multicolumn{1}{l}{ No } & Nama Banjar & Luas Wilayah \\
\hline 1. & Br. Dinas Sangkungan : & $75,617 \mathrm{Ha}$ \\
2. Br.Dinas Tabu : & $40,208 \mathrm{Ha}$ \\
3. Br.Dinas Tangkup Anyar : & $119,680 \mathrm{Ha}$ \\
4. Dinas TangkupDesa : & $31,115 \mathrm{Ha}$ \\
\hline \multicolumn{2}{r}{ TOTAL } & $266,620 \mathrm{Ha}$. \\
\hline
\end{tabular}

Sumber : Pengabdian, 2020

Wilayah desa Tangkup sebagian besar berupa pesawahan dan pekebunan. Apabila memasuki usia panen, masyarakat Desa Tangkup akan menjual hasil kebun ke kota Klungkung maupun dijadikan konsumsi pribadi. Walaupun masyarakat Desa Tangkup lebih banyak bermata pencaharian sebagai petani, namun kebanyakan dari mereka hanya mengelola sawah yang bukan milik sendiri (petani penyakap) karena sebagian besar sawah dimiliki penduduk yang tidak berasal dari Desa Tangkup. Oleh sebab itu, kepala desa setempat, mata pencaharian yang dominan di Desa Tangkup adalah sebagai buruh tani. Selain menjadi buruh tani, setiap keluarga yang ada di Desa Tangkup juga membuat kerajinan tangan berupa kain tenun, dimana pengerajin tenun yang ada di Desa Tangkup telah memiliki pengepul sendiri yang bekerjasama dengan masing-masing kepala keluarga yang ada di desa tersebut. Harga tenun pun telah dipatok oleh para pengepul, dan hasil tenun tersebut dibawa ke daerah Klungkung untuk dipasarkan. Apabila kerajinan ini dikembangkan lagi dan diberikan brand tersendiri yang berasal dari Desa Tangkup, tentu harga tenun akan menjadi lebih tinggi dibandingkan apabila hasil tenun tersebut diambil pengepul dan dipasarkan di daerah Klungkung. Meskipun brand belum tercipta, namun warga perajin merasa puas karena produk yang dihasilkan segera dibeli pengepul sehingga segera memperoleh hasil untuk produksi berikutnya.

\section{b. Kondisi Demografis}

Jumlah penduduk Desa Tangkup seluruhnya adalah $882 \mathrm{KK}$ yang tersebar dalam empat banjar. Dalam beberapa tahun terakhir tampak jumlah penduduk tetap atau tidak ada penambahan yang signifikan. Kiranya konsep keluarga berencana sudah diterapkan dan hampir setiap keluarga hanya memiliki 2 anak saja. Jumlah penduduk tetap pada bulan Februari 2021 sesuai yang tercatat pada papan demografi desa berjumlah yakni 3435 jiwa. Jumlah penduduk secara rinci ditampilkan pada tabel berikut. 
SAVE: Synergy and Society Service

Vol 1, No 2, Desember 2021 hal. 67 - 78

(Ni Wayan Mekarini ${ }^{1}$, Putu Agus Prayogi ${ }^{2}$, I Ketut Sutapa ${ }^{3}$ )

Tabel 2

Komposisi Penduduk Desa Tangkup

\begin{tabular}{|c|c|c|c|c|c|c|c|c|c|c|c|c|c|c|c|c|c|c|}
\hline \multirow{3}{*}{ DUSUN } & \multicolumn{6}{|c|}{ JUMLAH PENDUDUK AWAL } & \multicolumn{5}{|c|}{ JUMLAH PENDUDUK AKHIR } & \multicolumn{7}{|c|}{ MATA PENCAHARIAN } \\
\hline & \multirow{2}{*}{ JUMLAH KK } & \multicolumn{2}{|c|}{ WNI } & \multicolumn{2}{|c|}{ WNA } & \multirow{2}{*}{$\begin{array}{c}\text { JUMLAH } \\
\text { JIWA } \\
\end{array}$} & \multicolumn{2}{|c|}{ WNI } & \multicolumn{2}{|c|}{ WNA } & \multirow{2}{*}{\begin{tabular}{|c|} 
JUMLAH \\
JIWA
\end{tabular}} & \multirow{2}{*}{ TANI } & \multirow[b]{2}{*}{ BURUH } & \multirow[b]{2}{*}{ TUKANG } & \multirow[b]{2}{*}{ DAGANG } & \multirow[b]{2}{*}{ PNS } & \multirow[b]{2}{*}{ ABRI } & \multirow[b]{2}{*}{ POLR } \\
\hline & & $\mathrm{L}$ & $P$ & $\mathrm{~L}$ & $\mathrm{p}$ & & $\mathrm{L}$ & $P$ & $\mathrm{~L}$ & $P$ & & & & & & & & \\
\hline SANGKUNGAN & 250 & 496 & 477 & - & - & 973 & 496 & 477 & - & - & 973 & 364 & 121 & 32 & 17 & 5 & 2 & - \\
\hline TABU & 179 & 332 & 305 & - & - & 637 & 332 & 306 & - & - & 638 & 144 & 38 & 10 & 18 & 3 & - & 1 \\
\hline TANGKUP ANYAR & 368 & 792 & 697 & - & $\cdot$ & 1489 & 792 & 697 & - & - & 1489 & 284 & 656 & 29 & 30 & 19 & 1 & - \\
\hline \multirow[t]{3}{*}{ TANGKUP DESA } & 85 & 168 & 168 & - & - & 336 & 168 & 168 & - & - & 336 & - & - & - & - & 14 & - & 2 \\
\hline & 882 & & & & & 3435 & & & & & 3436 & & & & & & & \\
\hline & & & & & & & & & & & & & & & & & & \\
\hline
\end{tabular}

Sumber : Pengabdian, 2020

Luas wilayah persawahan menyebabkan sebagain besar penduduk bekerja sebagai petani. Selain menanam padi, Sebagian juga menamam bunga yang dapat digunakan dalam pembuatan canang dalam pelaksanaan agama setempat atau juga dijual kepada pengepul luar desa. Tidak jauh daro pemukiman penduduk tampak bebukitan hijau yang bahkan mengelilingi desa. Bukit ini menjadi spot menikmati pemandangan kota Klungkung dan sekitarnya di malam hari. Selain menjadi buruh tani, setiap keluarga yang ada di Desa Tangkup juga membuat kerajinan tangan berupa kain tenun, dimana pengerajin tenun yang ada di Desa Tangkup telah memiliki pengepul sendiri yang bekerjasama dengan masing-masing kepala keluarga yang ada di desa tersebut. Harga tenun pun telah dipatok oleh para pengepul, dan hasil tenun tersebut dibawa ke daerah Klungkung untuk dipasarkan. Apabila kerajinan ini dikembangkan lagi dan diberikan brand tersendiri yang berasal dari Desa Tangkup, tentu harga tenun akan menjadi lebih tinggi dibandingkan apabila hasil tenun tersebut diambil pengepul dan dipasarkan di daerah Klungkung. Meskipun brand belum tercipta, namun warga perajin merasa puas karena produk yang dihasilkan segera dibeli pengepul sehingga segera memperoleh hasil untuk produksi berikutnya.

\section{METODE PELAKSANAAN}

Metode pengabdian dilaksanakan secara bertahap mulai dari observasi lapangan, perkenalan dengan apparat desa dan menyesuaikan program kegiatan dengan kebutuhan desa. Hal ini dilaksanakan agar manfaat kegiatan benar-benar dapat dirasakan desa serta dapat dikerjakan oleh tim kerja pengabdian. Mata kegiatan mencakup banyak aspek terkait persiapan menjadi desa wisata, seperti kebersihan lingkungan, keindahan taman desa, pengenalan kebudayaan, pendidikan dan keagamaan. Terkait dengan persiapan tersebut maka tim juga melaksanakan identifikasi potensi alam dan budaya, makanan khas dan penyajian, penyiapan SDM dan prasarana desa. Rincian Langkah kerja disajikan dalam tabel di bawah ini. 
Tabel 3

Metode Pengabdian

\begin{tabular}{|c|c|c|}
\hline No & Jenis Kegiatan & Kegiatan \\
\hline 1 & Pengenalan & $\begin{array}{l}\text { Observasi menuju Desa Tangkup dan mengunjungi } \\
\text { Taman Asta Gangga. }\end{array}$ \\
\hline 2 & Pembukaan & $\begin{array}{l}\text { Pembukaan KKN di desa Tangkup dan penyerahan } \\
\text { mahasiswa kepada desa. }\end{array}$ \\
\hline 3 & Kegiatan utama & $\begin{array}{l}\text { Melakukan identifikasi potensi budaya } \\
\text { a. Perajin tenun cag-cag } \\
\text { b. Topeng Nong-Nong Kling } \\
\text { c. Makanan khas: jaja tulud, pesor, sangait } \\
\text { d. Analisis hambatan menuju desa wisata }\end{array}$ \\
\hline 4 & Kegiatan utama & $\begin{array}{l}\text { Melakukan identifikasi potensi alam } \\
\text { a. Taman Asta Gangga (TAG) } \\
\text { b. Permandian Sungai Yeh Gangga } \\
\text { c. Pancoran } \\
\text { d. Pura Taman Beji } \\
\text { e. Modifikasi penyajian makanan khas lokal } \\
\text { f. Analisis ancaman menuju desa wisata }\end{array}$ \\
\hline 5 & Kegiatan utama & $\begin{array}{l}\text { Sosialisasi dan Pelatihan } \\
\text { a. Sosialisasi dan Persiapan pembentukan Pokdarwis } \\
\text { b. Sosialisasi CHSE, dan Sapta Pesona } \\
\text { c. Edukasi Bahasa Inggris dan Manajemen } \\
\text { d. Pelatihan pengolahan pangan tradisional dan cara } \\
\text { pemasaran }\end{array}$ \\
\hline
\end{tabular}

Sumber : Pengabdian, 2020

\section{HASIL DAN PEMBAHASAN}

\section{Idintifikasi Potensi Wisata}

Pelaksanaan kegiatan diawali dengan kegiatan identifikasi potensi wisata yang dimiliki oleh Desa Tangkup. Kegiatan identifikasi potensi wisata ini dilakukan dengan cara melakukan pengamatan diseluruh wilayah Desa Tangkup, serta melakukan wawancara dengan tokoh masyarakat, masyarakat dan karang taruna. Dari hasil identifikasi potensi wisata tersebut maka diperoleh hasil sebagai berikut. Potensi budaya Desa Tangkup mencakup berbagai budaya setempat mulai dari kerajinan tenun cag-cag, tarian barong Nong-Nong Kling, dan makanan khas. Desa Tangkup memiliki olahan jajanan tradisional yang dinamai Jajanan Tulud. Jajan Tulud ini merupakan jajanan yang dibuat saat ada upacara keagamaan. Jajanan Tulud sendiri saat ini akan di kembangkan menjadi olahan produk panganan yang di olah menjadi panganan yang dapat bernilai ekonomi. Dari potensi dari olahan pangan ini akan dikembangkan dengan cita rasa yang unik dan bervariasi. Diharapkan agar panganan ini menjadi perhatian dari masyarakat sekitar, dan dapat dinikmati juga oleh wisatawan yang berkunjung. 

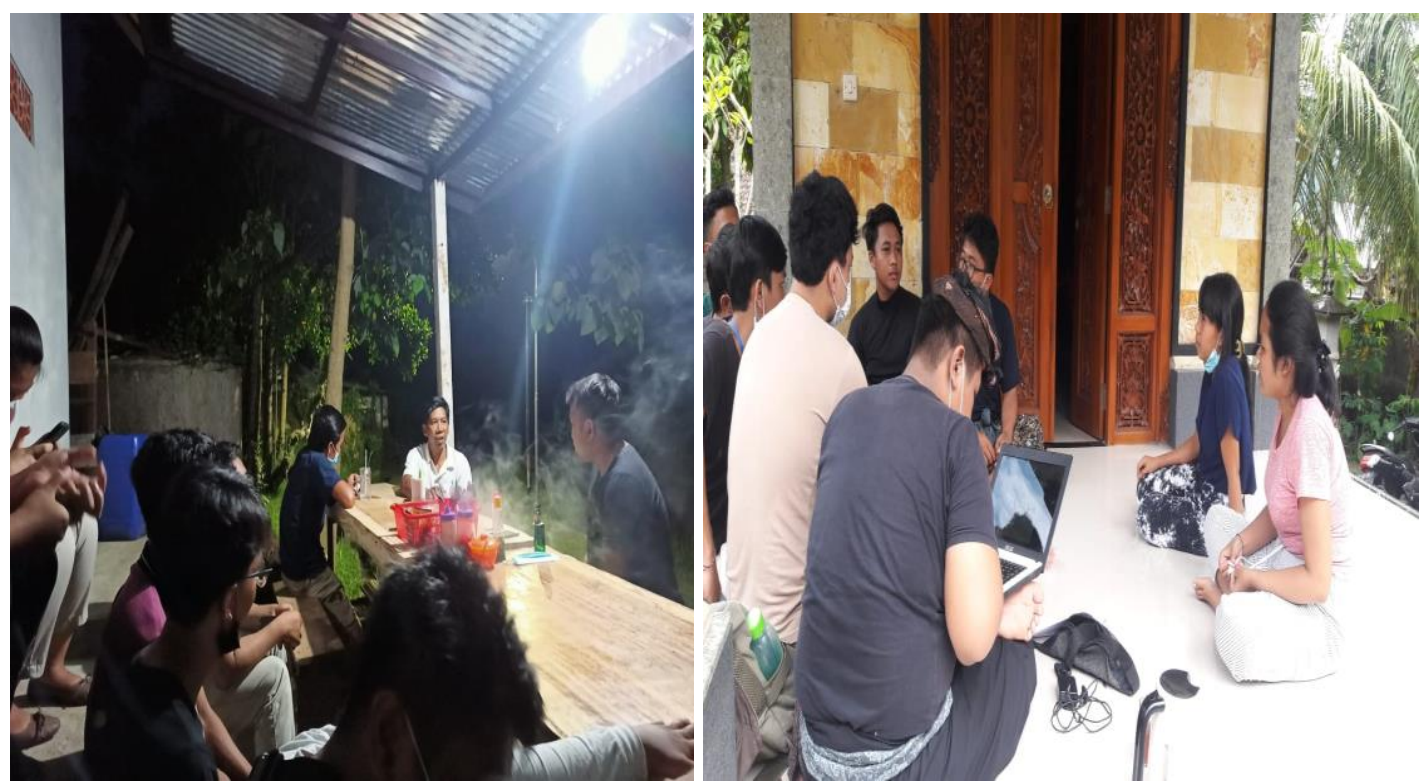

Gambar 1.

Wawancara dengan Prebekel Desa Tangkup dan Pengerajin Tenun Cagcag Dalam Identifikasi Potensi Wisata di Desa Tangkup

Sumber : Pengabdian 2020

Potensi alam meliputi daerah perbukitan yang mengelilingi sebagian wilayah Desa Tangkup, mulai dari bagian timur, utara, barat sampai selatan. Melalui bukit di bagian Barat Daya, dapat dilihat pemandangan indah ke arah Samudra Hindia, pesisir Klungkung, Gianyar, Denpasar, Bukit Jimbaran dan Patung Garuda Wisnu Kencana. Pemandangan sawah yang menghampar luas ditambah dengan aktifitas petani dalam bercocok tanam, menjadi daya tarik tersendiri untuk wisata alam..

Pada sisi barat, mulai dari utara ke selatan, terdapat Sungai Telaga Waja yang memiliki Air yang mengalir deras dengan beberapa jeram yang curam serta bebatuan di sepanjang sungai, menjadikan Sungai Telaga Waja sebagai spot rafting yang paling menantang di Bali. Selain menguji andrenalin, jalur rafting di Sungai Telaga Waja juga menawarkan pemandangan alam yang sangat indah. Sepanjang jalur rafting wisatawan akan disuguhkan pemandangan sawah dan beberapa spot air terjun yang menawan. Tidak mengherankan Sungai Telaga Waja menjadi primadona bagi wisatawan yang gemar melakukan kegiatan rafting. Sisi utara desa yang di kelilingi daerah perbukitan juga menawarkan keindahan alam yang menakjubkan. Pada pagi hari kita akan disuguhkan pemandangan matahari terbit yang menapjubkan. Di samping itu, terdapat sebuah bukit yang dijadikan taman rekreasi dengan panorama perbukitan serta terdapat wahana serta fasilitas yang dapat dinikmati oleh pengunjung 
seperti: seperti swing, flying fox, spot foto, fasilitas penginapan, restaurant, dan camping ground, terdapat juga suatu tempat untuk melakukan kegiatan spiritual seperti pemelukatan (pembersihan jiwa dan rohani), meditasi, yoga. Di tempat yang dikenal sakral yang terletak di bagian atas bukit Taman Asta Gangga tersebut, itu bahkan terkadang ada masyarakat yang memohon keturunan. Konon lokasi sudah ada sebelum terbentuknya Taman Asta Gangga, namun belum banyak diketahui oleh masyarakat. Dengan demikian, Desa Tangkup juga dilengkapi tempat ini memiliki potensi wisata religi (spiritual) yang didukung dengan keindahan alamnya.
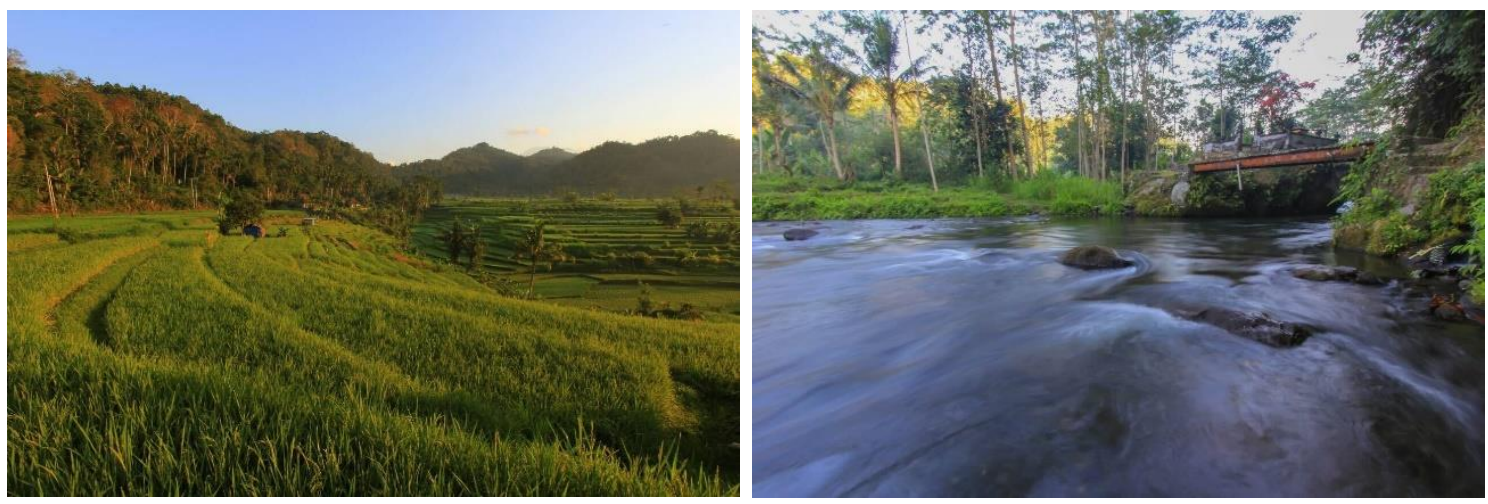

Gambar 2.

Potensi Alam yang ada Di Desa Tangkup Anyar

Sumber : Pengabdiaan, 2020

\section{Sosialisasi dan Pelatihan}

\section{Setelah}

dilakukannya

identifikasi potensi wisata, maka kegiatan pengabdian kepada masyarakat dilanjutkan dengan kegiatan sosialisasi dan pelatihan. kegiatan sosialisasi dilaksanakan dengan pemamparan materi mengenai Sadar Wisata, CHSE, dan Kepemanduan di Era New Normal. Sosialisai CHSE dan Kepemanduan di Era New Normal dilaksanakan di Taman Asta Gangga dengan peserta dari para karyawan Taman Asta Gangga, masyarakat, dan karang taruna. Kegiatan sosialisasi ini dilaksanakan oleh team mahasiswa yang dipandu oleh dosen pendamping. Kegiatan sosialisasi ini bertujuan untuk menyampaikan informasi terkait pentingnya CHSE didalam mempersiapkan diri menyonsong pariwisata Era New Normal, sehingga para pelaku wisata dan masyarakat bisa memahami dan mampu mempersiapkan diri lebih awal. 


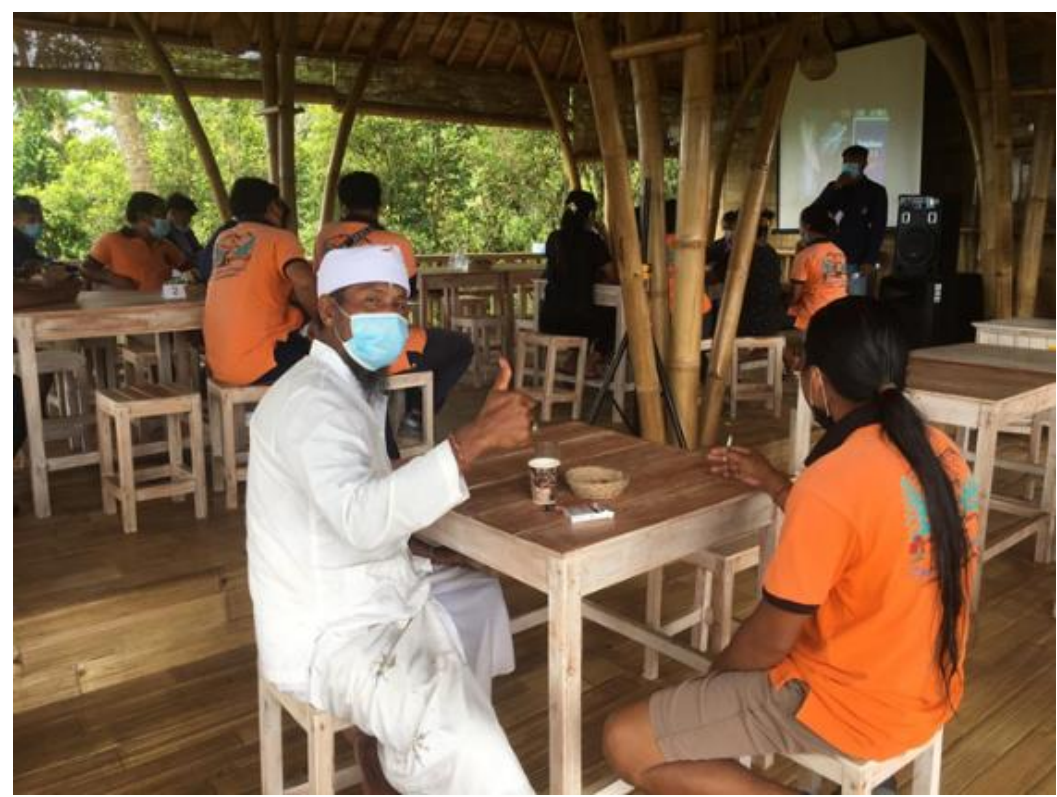

Gambar 3

\section{Sosialisasi CHSE dan Kepemanduan Era New Normal Di Taman Asta Gangga}

Sumber : Pengabdian, 2020

Sosialisasi mengenai sadar wisata dilaksanakan di balai serbaguna Desa Tangkup dengan peserta karang taruna, kelompok darma wanita, serta para pengurus desa. Kegiatan ini bertujuan untuk menyampaikan informasi mengenai pentingnya kesadaran masyarakat terhadap sapta pesona dan bagaimana cara menyiapkan diri dalam pengembangan kepariwisataan. Kegiatan sosialisasi ini dipandu oleh mahasiswa dengan nara sumber dari para dosen pendamping.
Berbagai informasi mengenai Sapta Pesona dan implementasinya disampaikan oleh para nara sumber. Para peserta yang kebanyakan dari karang taruna sangat antusias didalam pelaksanaan sosialisasi ini. Penerapan sapta pesona memang merupakan dasar pengembangan bagi tiap desa yang ingin mengembangkan potensi wisatanya. 


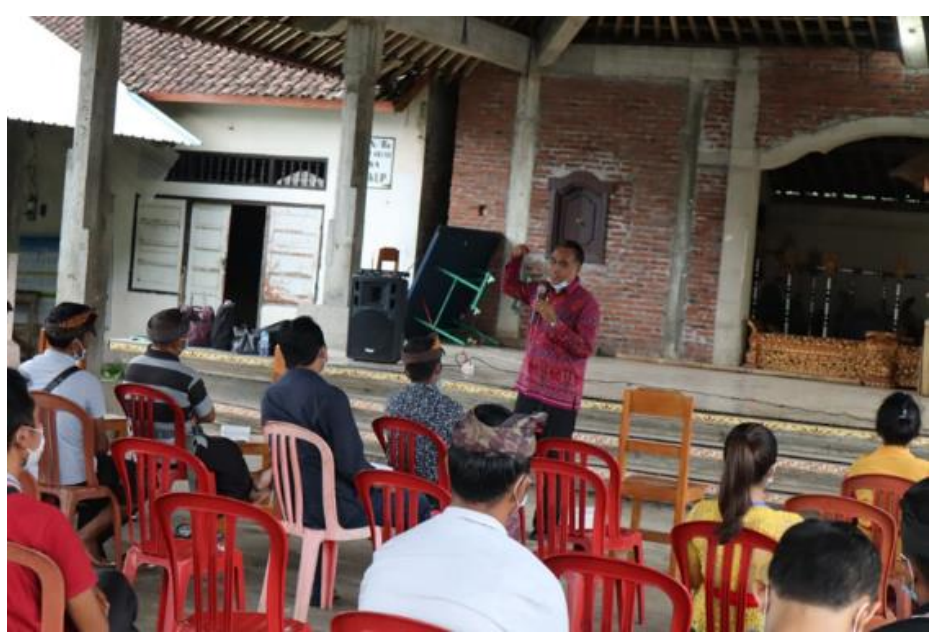

Gambar 4

Sosialisasi Sapta Pesona di Balai Masyarakat Desa Tangkup

Sumber : Pengabdian, 2020

Kegiatan sosialisasi berikutnya adalah kegiatan sosialisasi mengenai pembentukan pokdarwis (Kelompok Sadar Wisata). Kegiatan sosialisasi ini dilaksanakan di Kantor Prebekel Desa Tangkup dengan peserta para perangkat desa, pelaku wisata dan perwakilan LPM Desa Tangkup. Pembentukan Pokdarwis sangat dibutuhkan dalam upaya pengembangan Desa Wisata. Kegiatan ini dilaksanakan dengan narasumber berasal dari team dosen.

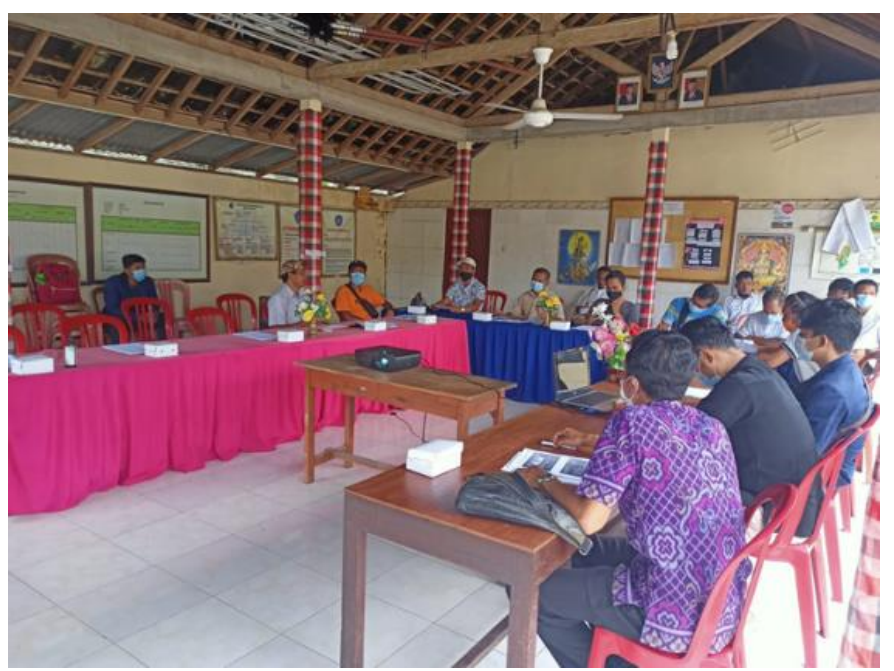

Gambar 5

Sosialisasi Pokdarwis di Kantor Prebekel Desa Tangkup

Sumber : Pengabdian, 2020

\section{KESIMPULAN}

Pelaksanaan pengabdian masyarakat dalam kegiatan KKN Fakultas Pariwisata Universitas
Triatma Mulya di desa Tangkup Kecamatan Sidemen Karangasem memberi kesempatan mahasiswa dan dosen pendamping terjun dan belajar 
langsung dari masyarakat. Mahasiswa membiaskaan diri berbicara dan berlaku sopan terutama ketika menggali informasi dari pemuka masyarakat. Program pengabdian masyarakat inin menghasilkan temuan bahwa Desa Tangkup memiliki luas wilayah 2,667 Km2 yang sebagian besar berupa lahan persawahan dan dikelilingi bukit yang hijau. Potensi wisata alam yang dimiliki oleh Desa Tangkup yaitu area persawahan yang terletak di Dusun Tangkup Anyar, daerah aliran sungai (DAS) yang terletak di Dusun Tangkup Desa, dan beberapa spot wisata seperti Taman Asta Gangga, spot rafting,di sungai Telaga Waja, pancuran yang ada di beberapa sudut desa. Potensi budaya berupa kain tenun cagcag yang merupakan produk khas Tangkup, jajanan tradisional yang dinamakan jaje tulud, tipat pesor dan sangait. Namun, dalam proses pengembangan dari produk jajanan ini menemui kendala terkait alat cetak tradisional. Kini, tidak banyak warga yang bertahan membuat jaja tulud yang biasanya dipakai untuk kebutuhan upacara. Terkait tipat pesor yang terbungkus daun bamboo dikembangkan dengan penyajian yang lebih elegan dengan cup. Dengan tampilan itu, pesor bisa lebih representative dan bernilai ekonomis dan diterima oleh wisatawan. Mahasiswa turut aktif dalam persiapan pembentukan Pokdarwis agar arah pengembangan desa menuju desa wisata terkelola dan terarah. Sejauh ini, pengelolan potensi Desa Tangkup masih ditangani mandiri dengan memanfaatkan lahan yang dimiliki terutama yang berada dekat daerah aliran sungai, berupa café, rafting, objek wisata Taman Asta Gangga dan rumah bambu yang sedang dibangun sebagai fasilitas wisata di bukit. Kegiatan lain terkait penyiapan SDM juga dilaksanakan sebagai persiapan kelak desa Tangkup mendapat status desa wisata rintisan.

Pihak desa diwakili perbekel sangat berharap mahasiswa turut membangkitkan potensi pariwisata Desa Tangkup, agar dikenal luas dan pengunjung menikmati keasrian desa yang subur permai ini melalui penyiapan SDM setempat untuk menyambut desa Tangkup yang tidak lama lagi menjadi desa wisata. Program Pengabdian masyarakat ini disambut baik oleh pihak desa dan masyarakat sehingga kegiatan ini perlu dilaksanakan secara berkelanjutan. Adapun rencana kegiatan kedepannya dalam pelaksanaan pengabdian masyarakat di Desa Tangkup ini adalah membentuk pokdarwis sebagai pengelola desa wisata serta memberikan pelatihan terhadap masyarakat desa mengenai pengelolaan akomodasi dan kepemanduan lokal.

\section{UCAPAN TERIMA KASIH}

1. Bapak Dr. Drs. I Ketut Putra Suarthana, MM, selaku Rektor Universitas Triatma Mulya Badung dan seluruh jajaran rektorat.

2. Bapak I Nengah Subadra, SS., M. Par., Ph.D., Selaku Dekan Fakultas Pariwisata Universitas Triatma Mulya Badung dan seluruh dosen pendamping.

3. Bapak Perbekel Desa Tangkup yang telah memberikan kesempatan dan kerja sama selama melaksanakan semua program yang telah kami lakukan. 
4. Bapak Bendesa Adat Tangkup yang telah memberikan dukungan dan kerja sama selama melaksanakan semua program yang telah kami lakukan.

5. Bapak Kelian Banjar Dinas di Lingkungan Desa Tangkup yang telah memberikan dukungan dan kerja sama selama melaksanakan semua program Pengabdian Masyarakat.

6. Bapak/Ibu perajin tenun/jajan lokal/penari tradisonal warga masyarakat Desa Tangkup yang telah memberikan banyak informasi dan dukungan dan kerja sama selama identifikasi potensi budaya berlangsung.

7. Karang Taruna Desa Tangkup yang telah memberikan dukungan dan kerja sama selama melaksanakan semua program berlangsung.

8. Pengelola dan seluruh karyawan Taman Asta Gangga yang telah ikut membantu dan bekerjasama selama melaksanakan semua program Pengabdian Masyarakat.

9. Pemuka desa dan seluruh masyarakat Desa Tangkup yang telah menerima dan memberi ijin pelaksanaan program Pengabdian Masyarakat serta mendukung pelaksanaan semua program.

\section{DAFTAR PUSTAKA}

Ismayanti, (2010). Pengantar

Pariwisata. Jakarta : Grasindo

Prayogi, Putu Agus (2018). Pengembangan Potensi Wisata Di Desa Tangkup Dengan Konsep Pariwisata Pedesaan Dan Pemberdayaan Masyarakat, Jurnal Perhotelan dan Pariwisata Januari - Juni 2018, Vol. 8, No. 1
Prayogi, Putu Agus. (2020).Strategi Pengembangan Daya Tarik Wisata Pantai Matahari Terbit Sebagai Destinasi Wisata Keluarga di Kota Denpasar. Jurnal Perhotelan dan Pariwisata (Hal 67-89), Issn:2088-8155, Juni 2020, Vol.10, No.1

Syafi, Muhammad, Djoko Suwandono, (2015). Perencanaan Desa Wisata Dengan Pendekatan Konsep Community Based Tourism (CBT) di Desa Bedono, Kecamatan Sayung, Kabupaten Demak. Jurnal Ruang ISSN: 1858-3881 Vol 1, No.2 2015.Semarang :Universitas Diponegoro

Tim. (2021). Pedoman Penulisan Laporan KKN. Badung: Fakultas Pariwisata Universitas Triatma Mulya.

Tim. (2021). Template Artikel Desiminasi Hasil KKN. Badung: Biro Kemahasiswaan Universitas Triatma Mulya.

Wisnawa, I Made Bayu, Agus Prayogi, Ketut Sutapa . (2019). Brand Loyalty Model For Developing Potential Tourist Attraction At Tangkup Village In Karangasem. International Journal of Multidisciplinary Educational Research, Issn: 2277-7881; Impact Factor 6.014; Volume 8, Issue 8(7)

Wisnawa, I Made Bayu, Agus Prayogi, Ketut Sutapa.(2020). Pengembangan Pariwisata Berkelanjutan Pada Wisata 
SAVE: Synergy and Society Service

Vol 1, No 2, Desember 2021 hal. 67 - 78

(Ni Wayan Mekarini ${ }^{1}$, Putu Agus Prayogi ${ }^{2}$, I Ketut Sutapa ${ }^{3}$ )

Pedesaan Di Bali Melalui Brand

Loyalty: Studi Kasus Desa

Tangkup, Sidemen, Karang

Asem Bali. Proshiding 